\title{
БИОЛОГОЭКОЛОГИЧЕСКИЕ ОСОБЕННОСТИ РАЗВИТИЯ И РАЗМНОЖЕНИЯ ФАСОЛЕВОЙ ЗЕРНОВКИ (Acanthoscelides obtectus Say.) В УСЛОВИЯХ ЛАБОРАТОРИИ
}

\author{
Брадовский В.А., Брадовская Н.П. Мардарь М.Д.
}

Институт генетики, физиологии и защиты растений АН Молдовы, Кишинев, Молдова.

E-mail:brad-alex@mail.ru

\begin{abstract}
When mass laboratory breeding of bean seeds (Acanthoscelides obtectus Say.), it should be taken into account that the hatching of larvae from eggs and their settlement of beans should take place in the dark. Subsequent phases of development and maintenance of beetles are carried out in natural light at an optimal temperature of 24-30 degrees with the use of bean seeds of the Belskaya 16 variety.
\end{abstract}

Key words: Acanthoscelides obtectus Say., temperature, humidity, breeding, beans

Успех создания и воспроизводства культур насекомых зависит от правильного выбора комплекса экологических факторов и их уровня. По литературным сведениям экологические факторы при массовом разведении оказывают двоякое действие витальное и сигнальное. Первое определяет границы и условия существования, а второе служит источником информации о состоянии экосистемы и ее возможных изменениях.

Из числа биотических факторов наиболее важными являются пища и внутривидовые отношения. Таким образом, основное внимание уделяется созданию оптимальных гигротермических и световых условий, оценке пищевого субстрата с точки зрения обеспечения физиологических потребностей вида и возможностей круглогодичного разведения, на удовлетворение специфических потребностей вида в снятии диапаузы, в укрытиях, местах откладки яиц и др. Поэтому в задачу 
исследований входила количественная реакция популяции фасолевой зерновки Acanthoscelides obtectus Say. на ее введение в культуру.

При оценке пригодности в качестве кормового субстрата для фасолевой зерновки семян различных бобовых культур провели серию кормоиспытательных выкормок.

Наблюдения за зерновкой, воспитанной при 26 градусах на горохе, бобах, конских бобах и фасоли показали, что биометрические характеристики и репродуктивная способность фитофага изменяются в зависимости от вида корма.

Показатели разведения, представленные в наших исследованиях свидетельствуют, что наиболее благоприятным кормовым субстратом для A. obtectus является фасоль.

Негативное влияние неспецифической кормовой культуры проявляется в более длительных сроках развития, уменьшении средних размеров жуков и снижении плодовитости. Так, продолжительность развития от яйца до имаго на естественном кормовом субстрате (при температуре $26^{\circ} \mathrm{C}$ ) равна 31 суткам. Этот же показатель на горохе равен 41 дням. (Fф > F 05, НСР $05=2.12$ ).

Средние размеры тела жуков, развивавшихся на неспецифическом корме на существенную величину меньше, чем на фасоли. Длина тела имаго, отродившихся из фасоли, в среднем равна $3.33=0.02$ мм, а размеры жуков, развивашихся на других бобовых культурах достигают всего 2.50 мм.

Перевод зерновки на естественные пищевые субстраты - заменители кормового растения сказывается в значительной степени и на ее репродуктивных способностях. Так, фактическая плодовитость "фасолевых" самок в 4 - 12 раз превышает плодовитость самок, развивающихся на горохе.

Депрессивное состояние фитофага при смене кормового растения связано, на наш взгляд, со структурой биополимеров, используемых насекомыми в качестве источника энергозатрат и пластических материалов, поскольку содержание влаги в семенах различных культур практически одинаковое.

Для подбора сорта фасоли, обеспечивающего наиболее высокий биологический потенциал разводимых насекомых в сочетании с максимальным использованием пищевого субстрата испытали четыре восприимчивых сорта фасоли и сортосмесь. Наблюдения за процессами внедрения и развития личинок, отрождением жуков позволили определить плодовитость самок и коэффициент использования субстрата.

В результате проведенных экспериментов было выяснено, что предложенные сорта фасоли значительно влияют на биологические особенности фасолевой зерновки. Так, процент отрождения жуков в зависимости от сорта колебался с 61.1 до 93.0\%. Максимальная фактическая плодовитость самок отмечена на сорте Бельская 16 $284.0=11.7$ яиц на одну самку, что в 1.5 - 4.5 раз превышает плодовитость самок, воспитанных на других сортообразцах.

Несмотря на то, что испытанные сорта не характеризуются высокой устойчивостью к зерновке как вредителю, было выяснено, что фасоль обладает по отношению к ней сортоспецифичностью, и наиболее привлекательным сортом является Бельская 16. Кроме того, этот сорт соответствует требованиям разведения в связи с обеспечением высокого уровня заселения семян и отрождения жуков.

Сравнительно низкое среднее количество внедрений в одно семя $(6.8=1.1)$, обусловленное их малыми размерами обеспечивает, тем не менее, высокий коэффициент использования субстрата - 0.80. Наиболее красноречивым показателем является количество яиц, полученных с единицы пищевого субстрата. Так, 100 г фасоли 
сорта Бельская 16 позволили получить около 1.5 г яиц зерновки, или 450 тысяч штук, что существенно превышает таковое количество в других вариантах.

Основываясь на вышеизложенном, в будущем при разведении фасолевой зерновки и для ее массового получения будут использоваться семена фасоли сорта Бельская 16.

В связи с пойкилотермностью насекомых температура их тела в очень большой степени зависит от температуры окружающей среды, которая и определяет интенсивность обмена веществ, темпы онтогенеза, продолжительность жизни и плодовитость, количество генераций, размеры тела, поведенческие реакции.

Установлена коррелятивная зависимость между величиной температуры и сроками развития зерновки. По мере повышения температуры от 18 до 30 градусов продолжительность развития сокращается.

Весь цикл развития от яйца до имаго длится от 27 суток при 30 градусах до 59 суток при 18.

Кривая скорости развития зерновки на значительном своем протяжении может быть сведена к прямой, отражающей увеличение скорости развития при повышении температуры окружающей среды. Так, при 18 градусах за сутки осуществляется $1.69 \%$ общего развития, а при 30 градусах - $3.8 \%$.

Влияние температуры окружающей среды существенно сказывается на показателях биологического потенциала зерновки, как выживаемости личинок I - го возраста, плодовитости самок, продолжительности жизни имаго.

Результаты экспериментов свидетельствуют, что низкие показатели заселения субстрата при 18 градусах в значительной степени обусловлены массовой гибелью личинок I - го возраста до 64\%. Большая часть внедрившихся личинок гибнет на последующих стадиях развития, и только $28 \%$ особей заканчивают развитие и выходят из зерен.

Жуки при этой температуре малоактивны, плодовитость в среднем 1.7 яиц на одну самку. При повышении температуры до 21 градуса выживаемость поздних стадий развития резко повышается и отрождение жуков составляет $79.0 \%$, но уровень гибели личинок I - го возраста остается высоким - 39 \%, при этом плодовитость самок достоверно не отличается от предыдущей.

Исследованиями установлено, что температурный оптимум фасолевой зерновки находится в промежутке 24 - 30 градусов. Между высокими показателями выживаемости личинок I - го возраста, отрождения имаго и плодовитостью самок при исследованных температурах на 5 \% уровне значимости нет существенной разницы.

При определении влияния влажности на развитие и жизнедеятельность зерновки принимали во внимание, что имаго ведут свободный образ жизни, в то время как личиночное развитие протекает внутри зерна. Поэтому учитывали относительную влажность воздуха и семян. Относительная влажность воздуха в пределах 60 - $90 \%$ при оптимальной температуре (в опытах - 26 градусов) не отражается на жизнедеятельности имаго и развитии личинок в зернах, что подтверждается и литературными данными.

Личинки I - го возраста, ведущие свободный образ жизни, имеют узкую зону оптимума: их нормальное отрождение из яиц и внедрение в семена фасоли отмечено при относительной влажности воздуха выше 70 \%. В этих условиях наблюдали практически 100 \%-ное отрождение личинок из яиц. Относительная влажность воздуха $60 \%$ обуславливала высыхание значительного количества яиц и гибель личинок, уровень отрождения которых не превышал 70 \%. 
Фасолевая зерновка развивается на зрелых семенах фасоли, что более благоприятно в физиологическом отношении, т.к. химический состав зрелых зерен относительно стабилизирован. При этом личинки довольствуются влагой, содержащейся в семенах. Зрелые семена фасоли содержат 11\% воды. Повышение ее доли влечет за собой следующие неблагоприятные для зерновки последствия: набухание и прорастание зерен;

разогревание кормового субстрата вследствие более интенсивного дыхания и обмена веществ семян; развитие бактериальной и грибной микрофлоры. Как следствие вышеперечисленных причин приводят к массовой гибели, развивающейся в семенах зерновки.

Таким образом, требования фасолевой зерновки к условиям среды различаются по фазам развития. Личинкам I - го возраста необходима относительная влажность воздуха выше 70 \%. Последующие стадии развития не столь чувствительны к этому фактору среды и успешно развиваются при влажности 60 - 90 \%. Оптимальной температурой всех фаз развития зерновки является промежуток 24 - 30 градусов.

В природе свет в сочетании с другими факторами среды оказывает прямое и косвенное влияние на насекомых, сказываясь на продолжительности развития, числе генераций, плодовитости, поведении. В условиях разведения действие светового фактора проявляется резче, чем в природе, т.к. в искусственных условиях индивидуальные возможности насекомых в реализации приспособительных реакций ограничены.

Специфическим потребностям вида должна соответствовать в первую очередь длина светового дня. Сокращение длительности светлого времени суток вызывает у насекомых своеобразную фотопериодическую реакцию, ведущую к диапаузе, которая является адаптацией к сезонной смене условий существования. Однако на развитие насекомых со слабо дифференцированными сезонными циклами длина светового дня не оказывает влияния. Для фасолевой зерновки, родиной которой являются субтропики Центральной Америки, диапауза как фотопериодическая реакция не характерна.

В наших климатических условиях перезимовка, осуществляемая в стадии имаго, в основном внутри зерен в хранилищах, а в природе - в очень теплые зимы, сопровождается репродуктивной диапаузой, легко снимаемой при попадании зерновки в благоприятные температурные условия.

Следовательно, смена светлого и темного времени суток сказывается только на поведенческих реакциях зерновки, но не на цикле ее развития.

Максимальная активность фасолевой зерновки наблюдается в светлое время суток. Имаго обладают четко выраженным положительным фототаксисом. Но слишком яркое естественное или искусственное освещение скорее оказывает на жуков раздражающее действие. При умеренном освещении поведение жуков более адекватно они исследуют садок, находящийся в нем субстрат, дополнительно питаются, активно спариваются и откладывают яйца. В темноте жуки малоактивны, почти не передвигаются.

В опытах исследовали влияние освещенности на развитие, отрождение, жизнедеятельность жуков. Выяснили, что развитие зерновки, воспитанной при естественной освещенности и в условиях темноты протекает одинаково. Из результатов исследований следует, что свет не является фактором, влияющим на отрождение зерновки при исследовании слоев фасоли от 1 до 5 см. Этот показатель колеблется между 90.0 и 92.3 \% на свету и 89.6 и 91.0 \% в темноте (F факт. < F 05). 
Учет количества откладываемых яиц показал, что свет не оказывает какого либо стимулирующего или угнетающего действия на процессы созревания и откладки яиц зерновкой.

Полученные результаты свидетельствуют, что и в условиях темноты жуки фасолевой зерновки ведут нормальную жизнедеятельность, только снижается лишь двигательная активность. При этом жуки, содержащиеся в темноте и при естественной освещенности в течение 10 дней откладывают существенно неотличимое количество яиц $(124.2=2.7$ и $129.6=1.5$ яиц / самку соответственно, F факт. $<$ F 05).

Значительное влияние изучаемый фактор оказывает на процесс заселения кормового субстрата личинками. Отрождающиеся из яиц личинки фасолевой зерновки обладают отрицательным фототаксисом. При инкубации яиц на свету основная масса отрождающихся личинок концентрируется под подстилающей бумагой, в то время как в темноте они равномерно распределяются по всему объему садка.

Исследованиями установлено, что в темноте личинки равномерно распределяются по фасоли, и, вне зависимости от толщины ее слоя. Заселения зерен личинками колеблется между 75.3 и 78.6\%. При этом среднее количество внедрений в одно семя снижается незначительно - с 7.9 (1 см) до 5.8 - 6.0 (2 - 5 см).

При заселении фасоли на свету просматривается обратная зависимость между этими показателями и толщиной слоя фасоли. С увеличением высоты слоя фасоли от одного до пяти сантиметров заселения снижается соответственно с 75.0 до $33.0 \%$, а среднее количество внедрений - с 5.9 до 1.8 (НСР $05=2.2)$. Как показали наблюдения, незараженными при этом остаются верхние слои фасоли.

\section{Выводы}

При массовом лабораторном разведении фасолевой зерновки (Acanthoscelides obtectus Say.) следует учитывать, что отрождение из яиц личинок и заселение ими фасоли должно протекать в темноте. Последующие фазы развития и содержание жуков осуществляются при естественном освещении при оптимальной температуре в пределах 24 - 30 градусов с использованием семян фасоли сорта Бельская 16.

\section{Библиография}

1. Анисимов А.И. Необходимость и возможность реадаптации лабораторных популяций насекомых к естественным условиям обитания. Тез. докл. I Всесоюз.конф. по промышленному разведению насекомых. Москва, 1986, с.7.

2. Булыгинская М.А. Влияние длительного разведения яблонной плодожорки на ее биологические показатели. Тез. докл. I Всесоюз.конф. по промышленному разведению насекомых. Москва, 1986, с.63.

3. Захваткин Ю.А. Таблицы выживания - для сравнения и оценки искусственных сред. Защита растений. 1981, №1, с.18-19.

4. Злотин А.З. Теоретическое обоснование массового разведения насекомых. Энтомол. Обозрение. 1981, №3, с. 494-510.

5. Злотин А.З. Техническая энтомология. Киев, Наукова думка, 1989. С. 1-182. 